\title{
POSIÇÃO DO PACIENTE PARA CIRURGIA E IMPLICAÇÕES NO CUIDADO DE ENFERMAGEM
}

\author{
Brigitta E. P. Castellanos* \\ Estela Regina Ferraz**
}

CASTElllanos, B. E. P. \& FERRAZ, E. R. Posição do paciente para cirurgia e implicações na assistência de enfermagem. Rev. Esc. Enf. USP, São Paulo, 14(1): 73-82, 1980.

Este trabalho focaliza a importância da posição do paciente em intervenção cirúrgica $e$ suas implicações na assistência de enfermagem.

A tarefa de colocar na mesa de operações o paciente que vai ser submetido a cirurgia é uma atividade que requer a participação da equipe de enfermagem, sendo necessário que esta conheça princípios de anatomia e fisiologia e saiba aplicá-los e tenha habilidade no manejo da mesa cirúrgica e de seus acessórios.

A mesa cirúrgica, devido à sua posição elevada do solo, sua pouca largura e ausência de grades, não é muito confortável ao doente. A utilização de diferentes angulações de suas partes (cabeceira, tronco, membros e coxim lcmbar) ou de acessórios auxiliares (perneira metálica, suporte de braço e ombreira) aumenta a responsabilidade da equipe de enfermagem quanto à prevenção de desconfortos desnecessários e de acidentes e complicações pós-operatórias, decorrentes de posições inadequadas durante o ato anestésico-cirúrgico.

Modelos modernos de mesas têm facilitado bastante a segurança e efetividade da posição do paciente, permitindo, ao cirurgião, facilidade no acesso ao local a ser tratado e, ao anestesista, a manutenção da permeabilidade das vias aéreas.

Uma boa mesa cirúrgica que se adapta a uma série de usos é um bom investimento econômico, por permitir flexibilidade na sua utilização em diferentes técnicas e especialidades cirúrgicas.

Acessórios adicionais à mesa cirúrgica, tais como travesseiros, sacos de areias e coxins de vários tamanhos e formatos são utilizados para apoiar as diferentes estruturas anatômicas dos pacientes e para atender às preferências dos cirurgiōes, quanto ao posicionamento especial.

Familiaridade com estes equipamentos é fundamental à sua utilização apropriada e efetiva, bem como à avaliação de sua utilidade na prática, levando-se em consideração o paciente, as pessoas que o manusearão, o cirurgião e o custo.

\section{Fatores Anatômicos e Fisiológicos}

A utilização adequada do equipamento e dos acessórios requer consideração dos fatores anatômicos e fisiológicos envolvidos na posição do paciente. Quando o doen-

* Professor Assistente da disciplina Enfermagem em Centro Cirúrgico da EEUSP - Mestre em Enfermagem.

* * Auxiliar de Ensino da disciplina Enfermagem em Centro Girúrgico da EEUSP. 
te é submetido a analgesia ou a anestesia local, ele mantém seus reflexos e pode comunicar seu desconforto ou sua dor; nos casos de anestesia regional ou geral, a má posição já é mais difícil de ser detectada, pois não é percebida pelo doente, e, conseqüentemente, o "circulante" de sala terá que utilizar sua capacidade de observação, para evitar possíveis lesões temporárias ou permanentes.

A anestesia geral deprime os Sistemas Nervosos Central e Autônomo, alterando a homeostase circulatória e respiratória. Doenças pré-existentes, como obesidade, diabetes, enfisema, artrite reumatóide e insuficiência cardíaca agravam o efeito da posição na mesa.

A boa posição cirúrgica é aquela que oferece o máximo de segurança ao paciente, com o mínimo de desconforto possível, e que facilite o ato cirúrgico. 0 momento para a colocação do paciente em posição é determinado pelo anestesista e a sua execução é de responsabilidade da equipe de enfermagem, sendo esta auxiliada pelo médico-anestesista, que se incumbirá de cuidar da cabeça do doente e das extensões do aparelho de anestesia, a fim de prevenir desconexões, compressões ou acotovelamentos.

Aconselha-se que o cirurgião ou seu assistente verifique a posição antes de antissepsia e da colocação dos campos cirúrgicos, para eventuais correções.

Ao colocar o paciente em posição cirúrgica, o pessoal da equipe de enfermagem precisa lembrar-se de que ele é um indivíduo e não simplesmente um caso cirúrgico e que, portanto, a posição, para ser adequada, deve:

- ser determinada pela natureza e sede da intervenção cirúrgica, tipo de anestesia e pela idade, altura, peso e condições gerais do paciente;

- proteger e interferir o menos possível com as funções vitais do paciente:

a) circulação, evitando compressões de vasos e estase sangüínea, facilitando o fluxo livre de infusões venosas e permitindo o controle da pressão arterial;

b) respiração, permitindo liberdade aos movimentos respiratórios e facilitando a indução anestésica em casos de anestesia inalatória ou endotraqueal;

- ser confortável, proporcionar adequado alinhamento corporal e proteger as funções básicas, os músculos, os nervos e as terminações nervosas, por meio de prevenção de compressões, abrasões e distensões; vimentos;

- avaliar e considerar, anteriormente à indução anestésica, anomalias e defeitos físicos, particularmente os que afetam os movimentos articulares, bem como os relativos às condições circulatórias, respiratórias e neurológicas;

- restringir a duração da posição especial ao mínimo necessário para executar determinada fase do ato cirúrgico.

Alterações respiratórias

A anestesia espinhal (intra e extradural) e a anestesia geral deprimem a função respiratória, seja por ação sobre os centros respiratórios, seja paralisando ou re- 
laxando os músculos respiratórios (intercostais e diafragma). A estes efeitos colaterais da anestesia podem ser somados outros conseqüentes à posição cirúrgica.

Toda deficiência respiratória repercute sobre as funções cardiovasculares, cerebrais e hepáticas principalmente.

A posição influencia na respiração de três maneiras:

1 - altera o volume sangüíneo nos capilares pulmonares e, como consequencia, o volume de sangue para a oxigenação;

2 - diminui a capacidade de expansão alveolar, levando à diminuição da oxigenação;

Qualquer dessas alterações leva à hipoventilação.

A posição de Trendelemburg proporciona o deslizamento das vísceras abdominais na direção do tórax, permitindo melhor exposição pélvica, mas seu peso sobre o diafragma, acrescido do aumento de volume de sangue pulmonar, pode diminuir a expansibilidade pulmonar, diminuido assim o fator ventilação-perfusão e repercutindo nas trocas gasosas.

A posição lateral dificulta a expansão do hemitorax correspondente, bem como o controle da aspiração de secreções deste pulmão. A posição ventral altera a adequada expansão respiratória no sentido anterior (torácica e abdominal).

A exagerada flexão das coxas na posição ginecológica dificulta a função respiratória pelo aumento da pressão intra-abdominal.

\section{Alterações cardiovasculares}

A adequada circulação de sangue depende da força propulsora do coração, do tonus muscular e da expansão fisiológica da caixa torácica. Durante a intervenção cirúrgica a força propulsora do coração pode estar deprimida pela anestesia, pela hipotermia e pela posição do paciente. A anestesia tem ação relaxadora sobra a musculatura em geral, havendo, conseqüentemente, perda do tonus vascular. A sucção e propulsão sobre a veia são restringidas pela diminuição da expansibilidade torácica, pois diminui a pressão negativa intra-abdominal.

A diminuição da expansão pulmonar provoca a diminuição da área de hematose, produzindo a hipóxia, que pode ter como conseqüência perturbações cardiovasculares tais como: súbitas paradas cardíacas ou choques que, iniciados no transoperatório, podem levar o doente à morte no pós-peratório imediato.

A anestesia, tanto geral como regional, geralmente causa dilatação dos vasos periféricos, reduzindo o volume de retorno venoso ao coração, aos pulmões, e, portanto, a redistribuição de sangue ao organismo. Além disso, os centros nervosos, sob o efeito da anestesia, ficaram com sensibilidade diminuída às alterações de pressão. Tudo pode ser agravado pela posição não adequada do paciente.

Ainda no aparelho cárdio-vascular podem ocorrer isquemias localizadas ou regionais, conseqüentes à compressão de troncos vasculares; admite-se também que a posição de Trendelemburg acentuada pode trazer esvaziamentos venosos, colaba- 
mento e contatos das paredes venosas, lesando o endotélio e facilitando o aparecimento de tromboflebites pós-operatórias.

A má circulação também pode ocasionar paralisias isquêmicas.

Abduções exageradas podem causar lesões vasculares, assim como tromboses podem ser conseqüientes às pressões, restrições ou pesos colocados sobre o paciente.

\section{Alterações neurológicas}

Paralisias podem ser causadas por abduções forçadas ou de longa duração e por estiramentos, bem como por isquemias dos elementos nervosos devido à compressões duradouras.

Pressões, mesmo por curto espaço de tempo, podem causar desde perda de sensibilidade até perda de capacidade motora.

A má posição cirúrgica gera áreas de pressão que podem resultar em úlcera de decúbito. Num estudo citado por FOSTER et alii ${ }^{1}$ feito nos EUA, com 100 pacientes submetidos a cirurgia de até duas horas, houve, em $13 \%$, a escara de decúbito. A causa principal é a má distribuição do peso corpóreo quando o indivíduo está deitado sobre uma superfície dura, ocorrendo concentração em proeminências ósseas, o que acarreta injúria dos tecidos circunvizinhos. A duração da pressão é de maior importância do que a sua intensidade.

Os nervos cubital, mediano e radial podem ser comprimidos se o braço ficar sem apoio na borda da mesa cirúrgica. A queda do cotovelo e o contato com o metal duro e frio da borda da mesa cirúrgica podem provocar lesões do nervo lunar sobre o epicôndilo do úmero.

Lesões dos nervos safeno, ciático e poplíteo interno podem ser conseqüentes à compressão da perneira metálica sobre o membro inferior.

Lesões do plexo braquial podem ser provocadas seja pela tração sobre o pulso, quando, em posição de Trendelemburgo, não são colocadas ombreiras, seja pela compressão das ombreiras metálicas quando estas não se apoiam na articulação acrômio-clavicular ou, ainda, pela abdução forçada do braço e conseqüente estiramento do plexo.

\section{Alterações musculares}

A pressão sobre os músculos, quando o paciente está anestesiado, produzirá dor muscular e sensação de formigamento. Em estado normal, o individuo mudaria de posição.

Em cada uma das posições, pode ocorrer distensão muscular; exemplos: Na "semi-rose" ou "rose", o estiramento dos músculos do pescoço (esterno-cleido-mastoideo e trapézio); na "ginecológica" o estiramento dos músculos dos membros inferiores (sartório, quadríceps femoral). Em pacientes que permanecem em posição supina e com os braços em cruz, a equipe cirúrgica pade acidentalmente deslocar o braço num ângulo superior a $80^{\circ}$, provocando o estiramento musculo e, também, compressão dos nervos e vasos locais (plexo braquial, artéria subclávia, veia cefálica). 
Dependendo da natureza do ato cirúrgico, pode-se utilizar uma das posições: dorsal, semi-rose, rose, ginecológica, lateral, ventral e sentada.

Posição dorsal ou supina

É a posição mais comum, sendo a posição anatômica de repouso. $O$ paciente é geralmente anestesiado nesta posição e, posteriormente à indução, são efetuadas modificaçōes.

A posição dorsal é utilizada para aproximação de superfícies anteriores do corpo e para acesso às cavidades corporais maiores.

O paciente fica deitado de costas, com os braços ao longo do corpo, os membros inferiores estendidos e os pés ligeiramente separados. A posição da cabeça deve estar em alinhamento com a coluna vertebral. Um pequeno coxim abaixo da cabeça permite o relaxamento dos músculos trapézio e previne a distensão do pescoço. Flexão e torção podem causar contraturas no pescoço e interferir com a permeabilidade das vias aéreas. Para prevenir desconforto pós-operatório, tais como lombalgias e lesões na coluna, conseqüentes a contraturas, a coluna deve ser mantida em alimento com a bacia e, quando necessário, a curva lombar deve estar apoiada em um pequeno coxim.

Coxins abaixo dos joelhos são desaconselháveis, pois podem causar compressão no nervo poplíteo e na veia safena. Deve-se, também, proteger as proeminências do calcâneo de pressão prolongada, por meio de coxins .

Os membros inferiores devem ficar paralelos, sem cruzamento das pernas, para prevenir lesões nervosas na pantorrilha. Os pés devem estar apoiados, para prevenir flexão plantar, e deve-se evitar colocar os campos cirúrgicos sobre os dedos, pois :serão uma fonte de pressão.

As superfícies da pele corporal não devem estar em contato direto com a outra; a umidade advinda da perspiração e transpiração, de soluções de antissepsia ou de irrigação, contribuem para a irritação e maceração da pele.

Os braços devem ficar em repouso ao longo do corpo, com as mãos em posição de pronação (palmas para baixo). 0 "lençol móvel" da mesa cirúrgica pode ser utilizado para fixar os braços em toda a sua extensão e prevenir que fiquem pendentes nas bordas da mesa. A restrição no punho não é aconselhável devido ao perigo de garroteamento da mão ou lesão da pele e de nervos da extremidade superior, principalmente quando o cotovelo, braço ou antebraço desliza para a borda da mesa cirúrgica e permanece em contato com a sua extremidade metálica dura e fria.

Quando os braços são colocados em posição de abdução, devem estar apoiados em talas forradas e numa angulação não superior a $80^{\circ}$, para prevenir compresão do plexo braquial e oclusão das artérias subclávia e axilar.

Sua fixação é obtida por meio de uma tira de adesivo ou atadura, aplicada sobre a mão em pronação, na altura dos ossos carpo, evitando-se pressão exagerada para não dificultar a circulação sangüínea local. 
Esta posição é utilizada para cirurgias do pescoço. A cabeceira da mesa cirúrgica é abaixada aproximadamente em $10^{\circ}$, para estender a região do pescoço. Um coxim roliço e firme, de cerca de $8-10 \mathrm{~cm}$ de espessura, é colocado nas costas, sob os ombros do paciente, tendo-se o cuidado de manter a cabeça e os ombros em alinhamento; caso contrário, a incisão em colar não ficará equitativamente centralizada. Em alguns casos o cirurgião solicita a colocação do doente em posição de Fowler, para assegurar o conforto do paciente, com a mesa fletida em $20^{\circ} \mathrm{e}$ abaixamento da seção dos pés cerca de $20^{\circ}$. Esta ligeira flexão, com os pés aproximadamente na mesma altura da cabeça, proporciona melhor estabilização da pressão sangüínea.

Os braços, como na posição dorsal, são mantidos ao longo do corpo, utilizando-se o "lençol móvel" para restringílo .0 equipamento para o controle da pressão sangüínea e para a administração das infusões venosas será adaptado com extensões e ficarão aos pés da mesa cirúrgica, a fim de facilitar a assistência do médico-anestesista.

\section{Posição rose}

Utilizada para cirurgias de boca e pálato. A posição é dorsal, com a colocação da cabeça pendida por meio do abaixamento completo a cabeceira da mesa. O cirurgião fica sentado apoiando a cabeça do paciente em seus joelhos, a fim de evitar que o peso desta provoque o estiramento de ligamentos e músculos da regiáo cervical. Para evitar o deslizamento do paciente, utilizam-se ombreiras, devidamente acolchoadas, que deverão ser colocadas na altura da articulação acrômio-clavicular, para prevenir lesões do plexo braquial. Os braços são mantidos ao longo do corpo, restringidos com o "lençol móvel".

O banco onde se sentará o cirurgião deve permitir o controle de sua altura, a fim de que este possa, realmente, apoiar a cabeça do paciente.

\section{Posição ginecológica (ou de litotomia)}

É utilizada para o acesso aos órgãos pélvicos e genitais.

O paciente é colocado em posição dorsal; a seção dos pés da mesa cirúrgica é abaixada completamente, e os membros inferiores são elevados e abduzidos em perneiras metálicas, para haver exposição da região perineal.

$O$ apoio dos membros deve ser cuidadosamente controlado. Colocando-se a espinha ilíaca anterior do paciente alinhada com a perneira metálica e o nível das nádegas em alinhamento com a extremidade da mesa, consegue-se boa posição, com um mínimo de esforço. As nádegas não devem ultrapassar a borda da mesa porque quando a seção da mesa for abaixada, o peso do corpo sobrecarregará a região dorsal e distenderá os ligamentos e músculos lombossacros.

As perneiras metálicas necessitam de coxins que cubram toda a superfície do metal e que sejam adequadas para não pressionar os nervos e vasos da região poplítea e os tecidos moles das pernas; na sua colocação é necessária muita atenção 
para evitar rotação externa e abdução da coxa, o que distenderá os músculos, abdutores e o tendão da articulação coxo-femural.

A altura é ajustada ao comprimento dos membros inferiores do paciente. Isto previne pressão sobre os joelhos e sobre a coluna vertebral lombar.

A posição do paciente precisa ser simétrica: o períneo deve estar em alinhamento com o eixo longitudinal da mesa, a pelve, elevada e a cabeça e o tronco, em alinhamento. Isto auxiliará o cirurgião a identificar os limites anatômicos. Se necessário, será providenciado apoio para a cabeça e o pescoço e, em caso da mesa cirúrgica ser colocada em ligeiro Trendelemburg (para alinhar a cavidade perineal com a linha de visão do cirurgião), utilizam-se ombreiras adaptadas à articulação acrômio-clavicular.

A colocação dos membros inferiores na perneira metálica, já com o coxim, é efetuada segurando-se a região plantar do pé com uma mão e apoiando a perna, perto do joelho, com a outra mão. A perna é elevada e os joelhos são flexionados lentamente.

Os braços do doente não devem ficar ao longo do corpo, pois as mãos poderão atingir a borda final da mesa e estarão em perigo de ser lesados durante a manipulação das seções da mesa cirúrgica. Eles poderão ser apoiados em talas forradas, numa abdução não superior a $80^{\circ}$. Não devem ser colocados sobre o tórax, porque restringirão o movimento respiratório.

A colocação de instrumental pode afetar os nervos femural e obturador na região dos flancos, causando distúrbios sensoriais nos membros inferiores.

Qualquer mudança da posição do paciente para posição ginecológica precisa ser realizada com cuidado, pois afetará a hemodinâmica deste; os movimentos precisam ser lentos, para permitir ajustamento gradual à mudança. Músculos e articulações, que estão em estado de flacidez na perneira metálica, não devem sofrer estiramentos anormais durante estas mudanças. As pernas devem ser levantadas simultaneamente (e lentamente), apoiando-se as articulações em cima e em baixo para prevenir estiramento da musculatura lombosacral. O peso corpóreo está mais concentrado na região sacra e sinais de pressão podem ser verificados após horas.

\section{Posição lateral}

É utilizada para cirurgias de tórax, de rim e porção alta do ureter. E uma posição que requer o trabalho em conjunto do "circulante", do anestesista e do cirurgião (ou seu assistente).

a) Em cirurgia renal e da parte alta do ureter. Após a indução anestésica (em posição dorsal) o paciente é colocado sobre o lado oposto a da intervenção cirúrgica com a região lombar sobre o local do coxim renal da mesa cirúrgica. $O$ anestesista deve apoiar a cabeça e ombros do paciente, enquanto o circulante movimenta os quadris do mesmo. Estando na cabeceira da mesa cirúrgica, o anestesista coloca uma de suas mãos atrás do braço do paciente do lado afetado e a outra no lado oposto do tórax do doente. $O$ circulante, postando-se do lado a ser operado, coloca seus braços sob os quadris do paciente; ambos, circulante e aneste- 
sista, levantam simultaneamente o quadril e os ombros do paciente para colocar o lado afetado para cima. Os quadris são deslocados para trás em alinhamento com a borda do coxim da mesa cirúrgica, e as pernas são colocadas de modo a proporcionarem estabilidade, ou seja, a perna de baixo é flexionada na altura do joelho e do quadril e a perna superior permanece esticada; esta manobra também auxilia o alívio dos músculos abdominais.

O coxim renal da mesa cirúrgica é erguildo, sob a região lombar do pacienté, de modo a que a área entre a $12{ }^{\mathrm{a}}$ costela e a crista ilíaca seja elevada. Esta elevação é controlada pelo médico anestesista quanto à resposta cardiovascular fisiológica do organismo com relação ao aumento da pressão criada, especialmente na veia cava inferir.

A seção torácica da mesa cirúrgica é abaixada lentamente, o mesmo acontecendo com seção dos pés.

Prevenção de estiramento dos músculos abdominais devido ao peso das pernas nesta posição, em declive dos membros inferiores é também objetivo da colocação da perna inferior em flexão com a superior nela apoiada.

Um travesseiro ou coxim grande é colocado entre as pernas e outro menor é utilizado para o apoio do pé da perna de cima. A posição é mantida por uma tira de esparadrapo larga $(15-20 \mathrm{~cm})$ e bem longa, colocada na altura das nádegas, logo abaixo da crista ilíaca, e fixada em ambos os lados da parte inferior do tampo da mesa cirúrgica, afim de não haver possibilidade de soltar-se, o que poderia provocar a queda do doente.

A cabeça é apoiada com um pequeno coxim para manter a coluna e a nuca em bom alinhamento. Os ombros são estabilizacios pela posição dos braços: o braço superior é levemente flexionado na altura do ombro e o cotovelo é apoiado num suporte de braço forrado ou no próprio arco da mesa cirúrgica, bem forrado, sendo, neste caso, necessária sua fixação com atadura de crepe. Em ambos os casos é necessário que seja feita uma observação cuidadosa para evitar o contato dos membros com o metal destes tipos de apoio dos braços.

Um pequeno coxim no ápice da escápula, no espaço axilar, aliviará a pressão sobre o braço inferior.

b) Em cirurgia torácica. O procedimento para a posição é semelhante ao anteriormente descrito para cirurgia renal, com pequenas modificações: para aumentar os espaços intercostais, objetivando proporcionar maior exposição da área cirúrgica, coloca-se a perna superir do paciente fletida sobre a inferior que será mantida estirada. $O$ coxim renal da mesa cirúrgica não é utilizado, podendo-se em alguns casos, utilizar um coxim macio sob a região lombar, como apoio, e para proporcionar liberdade aos movimentos respiratórios. Quando a incisão é realizada até a região posterior do tórax, o braço é levemente tracionado para frente e para baixo, afim de afastar a escápula da reigão cirúrgica. Quando a incisão é mais anterior, a posição do paciente é somente em leve lateral (cerca de $45^{\circ}$ ), com a utilização de um coxim de apoio em toda a extensão do dorso.

Posição ventral (ou de pronação)

Utilzada para cirurgias do dorso, coluna e de varizes na face posterior do membro inferior. $O$ doente é mantido deitado sobre o abdômen, posição esta que 
reduz a capacidade vital, devido à pressão nas costelas inferiores e à pressão intraabdominal, que interfere com o funcionamento do diafragma.

Após a indução anestésica, em decúbito dorsal, o paciente é movimentado em dois tempos: o primeiro para a posição lateral, junto à borda da mesa cirúrgica e posteriormente para a posição ventral, por rotação. Com um braço no tórax do paciente e a mão sob a axila o anestesista segura firmemente o doente enquanto ele é colocado na posição lateral; com a outra mão apoiando a nuca do paciente e apoiando-lhe a cabeça em seu antebraço, a rotação é efetuada pela "circulante", que roda os quadris do paciente. A cabeça é colocada de lado, apoiada por um coxim, devendo-se verificar se não há danos para olhos e ouvidos, mantendo-se a nuca no mesmo nível da coluna. Dois coxins roliços são colocados do ombro até a crista ilíaca, em ambos os lados, e outro, em transversal, sob o corpo do paciente, na altura das cristas ilíacas, para elevar o seu tórax e permitir livre movimentação do diafragma e expansão dos pulmões, bem como para prevenir pressão sobre os seios, no caso de paciente do sexo feminino, ou sobre o escroto e pênis, em paciente do sexo masculino.

Um pequeno coxim deve ser colocado na região da flexão do pé para evitar pressão sobre os pés e flexão plantar e para manter numa angulação não inferior a $45^{\circ}$. Os braços podem ser colocados ao longo do corpo ou apoiados em talas forradass; por meio de flexão dos cotovelos e pronação das mão pode-se prevenir tensão na altura dos ombros. Deve-se flexionar o cotovelo do paciente, antes de efetuar algum movimento, para prevenir fraturas ou deslocamentos.

\section{Posição sentada}

É utilizada para cirurgias cranianas e amidalectomia em crianças. Geralmente, a mesa cirúrgica é especial. O paciente senta-se nessa mesa e adapta a cabeça no suporte já existente.

É a melhor posição para a respiração - praticamente não há restrição à expansão pulmonar. Nessa posição, há concentração do peso corpóreo na região sacral. As pressões nessa área podem afetar o nervo ciático, principalmente se o paciente é magro e se a mesa cirúrgica não estiver adequadamente acolchoada.

Deve-se colocar-lhe os braço sobre o abdômen, suportados por um coxim, ou então em abdução, em ângulo inferior a $80^{\circ}$, para facilitar a administração de medicações endovenosas.

É importante observar a colocação do suporte de pés e num ângulo não inferior a $45^{\circ}$ com as pernas, para assim reduzir a pressão na região sacra e prevenir a posibilidade de desenvolver "pé de aquino".

Lembrar sempre que o paciente é um indivíduo e não um caso. Para tanto, é necessário conhecer algumas peculiaridades do paciente, principalmente quanto a: articulação, peso corpóreo, idade, problemas respiratórios, circulatórios, comprometimentos neurológicos e sistema sensorial para, assim, individualizá-lo e atender as suas necessidades. Para a coleta desses dados, seria o ideal que fosse feita pelo pessoal de enfermagem visita pré-operatória, pelo menos aos pacientes potencialmente graves, ou então que recebesse essas informações da unidade de internação, como preconiza JOUCLAS ${ }^{2} \mathrm{em}$ sua ficha pré-operatória. 
Durante a operação deve-se verificar se o paciente está confortável; o seu pudor deve ser respeitado, evitando-se descobri-lo desnecessariamente. Enquanto ele estiver consciente, ser-lhe-ia explicado, passo a passo o que irá acontecer, para tranqüilizá-lo. Enfim, é objetivo proporcionar conforto e segurança para cada um.

CASTELlANOS, B. E. P. \& FERRAZ, E. R. Surgical positions and their implications in nursing care. Rev. Esc. Enf. USP, São Paulo, 14(1):73-82, 1980.

This article brings into focus the importance of the patients position during surgery and its implication for nursng care.

\section{REFERENGIAS BIBLIOGRAFICAS}

1. FOSTER, C. G. et alii. Effects of surgical positioning. AORNJ, Englewood, 30(2): 21-33, Aug. 1979.

2. JOUCLAS, V. M. G. Elaboração e avaliaçăo de um instrumento de comunicação que favoreça a assisténcia de enfermagem no transoperatório. São Paulo, 1977 (Dissertação de Mestrado - EEUSP).

\section{BIBLIOGRAFIA CONSULTADA}

ALVES, J. B. de R. Cirurgla geral e especializada. Belo Horizonte, Vega, Brasileira, Instituto Nacional do Livro, 1973 . cap. 2. p. 23-55.

BALLINGER, W. E. et alii. Alexander's care of the patient In surgery. 5. ed. St. Louis, Mosby, 1972. cap. 7. p. 137-55.

BERRY, E. C. \& KOHN, M. I. A técnica na sala de operaçōes. 4. ed. Rio de Janeiro, Interamericana, 1977. p. $57-70$

BROOKS, S M. Enfermeria de quirófano. México, Interamericana, 1977. p. $72-7$. 